\title{
Corelation of Physical and Biochemical Parameters of Human Seman in Addicats and Functional Impotants.
}

\author{
${ }^{1}$ S. S. Jadhav, ${ }^{2}$ Afroz Syeeda, ${ }^{3}$ Bhore Usha, ${ }^{4}$ Karadkhekar S. S., ${ }^{5}$ Dudhmal V. S. \\ 1,2,3,4,5 Department Of Physiology Government Medical Collage and Hospital, Aurangabad -431 001.
}

\begin{abstract}
This study was carried to study the effect of addiction and functional impotence on fertility of male. Semen analysis of 125 males was done. Five groups ware made $I^{\text {st group }}$ was of 25 fertile Chewers, Smokers, Alcoholics and Functional impotants; each contains 25 subjects. The Physical Parameters were volume, motility and sperm count while biochemical parameters were ascorbic acid and fructose. The total count and total motile count was significantly decreased in tobacco chewers, smokers and alcoholics. The total count was decreased in functional impotants' group but this was not significant, but decrease in total motile sperm count was significant. The ascorbic acid concentration in semen of these studied four groups was lowered as compared to control group. But this decreased concentration was not significant. This finding indicates that lower quality of semen contains low concentration of ascorbic acid. While another biochemical parameter fructose, its concentration is significantly increased in studied four groups as compared to control group. It shows that percentage of fructose in the semen depends on sperm concentration and it was inversely proportional to the sperm concentration. The present study indicates that addictions and functional impotence causes decrease in male fertility potential.
\end{abstract}

\section{Introduction}

Infertility is one of the most tragic of all marital problems. Despite recent advances in the treatment of infertility the problem could not be satisfactorily tackled so far for varied reasons. Unfortunately some married couples are infertile and infertility is a social stigma in our society. Lay people blame the woman for infertility but now it is known that in about $40 \%$ of infertile couples man is at fault and remaining $60 \%$ female partners are at fault. It can be said that the investigations of a childless couple may fail for the two main reasons namely ignorance and inadequate correlation of available information.

Fertility of male is evaluated by semen analysis, various physical and chemical parameters are studied in semen analysis. The pathogenesis of male infertility seems to be considered under two headings.-
a) As abnormal Semen
b) Functional impotence

Some factors having influence on semen causes abnormal semen. It is seen that alcohol also effects the male reproductive system .Chronic ingestion of alcohol results in diminished spermatogenesis. Decrease in sperm density and motility in male smokers was reported.

A variety of Factors influence the composition of semen. There has been little attention paid to the possible impact of tobacco \& alcohol on reproductive capacity. The important biochemical parameters are fructose \& aerobic acid concentration in semen. There are many contra lateral studies on their values in semen.

Other factor with influence infertility is functional impotence. Psychological conditions can influence fertility through their effect on some of the psychological process involved in conception. The entire process of reproduction is controlled by a delicate balance of the hormones of the body. Emotional conflicts can easily upset this balance and thus affect the ability to reproduce. Functional impotence is a type of psychological problem. As impotence is simply an impairment of penile erection, accurate term is a erectile dysfunction. If is of two types - physical or organic impotance and functional or psychological impotence $80 \% /$ to $90 \%$ are physical one and 8 to $9 \%$ functional impotence cases. Functional importance can be treated by psychotherapy. The attempt is to see if there is any impact of addiction and functional impotance on physical and biochemical parameters.

\section{Material And Methods}

Subject was divided into four groups. First group consist of normal subjects. Other two groups consists addicts \& functional impotance. Each group contains 25 subjects. It was seen that how the levels of ascorbic acid, fructose \& physical parameters get affected in addicts \& functional impotents. And how these subjects suffer from infertility problems.

The Following Performa was used during examination of subjects. 
History:

Name:

Ag e:

Sex:

Occupation:

Diet

Personal History:

Marriage History:

Emotional Status:

Past history:

Physical Examinations:

Height:

Weight:

Examinations of Genitals:

Examinations of Semen:

Appearance of Semen:

Volume:

Viscosity:

Microscopic Examination of semen:

Sperm count:

Morphology:

Motility:

Viability:

Biochemical parameters:

Ascorbic acid:

Fructose:

\begin{tabular}{|c|c|c|c|c|c|}
\hline GROUP/PARAMETERS & ASCORBICACID & FRUCTOSE(ml) & VOLUME(ml) & TOTAL MOTILE sperm(millions/ejaculate) & TOTAL SPERM(millions/ejaculate) \\
\hline 1.CONTROL GROUP & 5.35 & 358.2 & 2.9 & 158.2 & 180.46 \\
\hline 2.TOBACCO CHEWERS' & 4.712,P VALUES NS & 401.08 P VALUES SIGNIFICANT & 2.482 P VALUES NS & 50.68 P VALUES HIGHLY SIGNIFICANT & 104.28 P VALUES HIGHLY SIGNIFICANT \\
\hline 3.SMOKERS' & 4.5 P VALUES NS & 423.04 P VALUES HIGHLY SIGNIFICANT & IT 2.58 P VALUES HIGHLY SIGNIFICAN & NT 47.84 P VALUES HIGHLY SIGNIFICANT & 789.2 P VALUES HIGHLY SIGNIFICANT \\
\hline 4.ALCOHOLICS' & 4.92 P VALUES NS & 464.92 P VALUES HIGHLY SIGNIFICANT & IT 2.78 P VALUES NS & 41.82 P VALUES HIGHLY SIGNIFICANT & 71.82 P VALUES HIGHLY SIGNIFICANT \\
\hline 5.FUNCTIONAL IMPOTANTS & S 4.123 P VALUES NS & 371.6 P VALUES SIGNIFICANT & 2.88 P VALUES NS & 150.2P VALUES SIGNIFICANT & 140.4 P VALUES NS \\
\hline
\end{tabular}

\section{Observation}

Table. Shows ascorbic acid concentration in five groups. The ascorbic concentration goes on decreasing from group 1th to Vth group. It is highest in control group, than other groups. It shows that as quality of semen goes on decreasing, ascorbic acid concentration goes on decreasing. It also indicates that as ascorbic acid goes on decreasing, fertility also decreases, it means that tobacco, and alcohol \& functional impotence affect ascorbic acid levels in semen. In some studies done by others same observation is noted. Statistical "P" values are determined by applying "T" test, which are not significant.

Table Shows fructose concentration in five groups. It goes on increasing form $1{ }^{\text {st To }} \mathrm{V}^{\text {Th groups }}$. It proves that as sperm density goes on decreasing fructose concentration goes on increasing. Thus there is inverse relation. Some workers observed there is no definite inverse relationship. But others demonstrated these relationships. Statistical ' $\backslash$ ' $P$ ' Values for fructose from $2{ }^{\text {nd to }} 5^{\text {th group }}$ are significant.

It means that smoking \& alcohol drinking affects the sperm production \& fertility.

Table Shows volume of semen in ml, decreasing from $1^{\text {th }}$ to $5^{\text {th }}$ with indicates that there is no much any change in Volume of semen. 'P' values are also not significant.

Table Shows total motile sperm count. Tobacco clewing, smoking \& alcohol affect the motile count. In $5^{\text {th }}$ group slight reduction, ' $\mathrm{P}$ ' values are also significant indicating motility reduced in addict's \& functional impotants.

Table Shows total sperm count in millions / ejaculate. It is decreasing in remaining groups. In functional impotant's group decreases due to emotional disturbances, there is hormonal imbalance taking place. The studies also show that emotional upset can disturb the hormonal balance \& reproduction.

IV Th group also called functional impotant $\square$ s group contained 25 subjects, having history of functional impotence.

The semen samples were analyzed for volume motility \& sperm count. The ascorbic acid \& fructose levels were obtained calorimetrically.

Both these physical \& biochemical parameters were compared between control group, tobacco chewers, smokers, alcoholics, and functional impotant's group. 


\section{Discussion}

Present work was planned to study correlation of physical \& biochemical parameters of human semen in addicts \& functional impotants.

The work was carried on 125 subjects, they were taken randomly.

Their wives were attending the Department of Obstetrics \& Gynecology, Govt, Medical Collage\& Hospital Aurangabad. They were investigated in Govt. Medical Collage \& Hospital Aurangabad.

The 125 subjects were arranged in five groups. Each group contains 25 subjects $.1^{\text {st }}$ group is called fertile group or control group. 2nd group contained 25 subjects having history of tobacco chewing since $10-12$ years. They use to take 2-3 packets of $\square$ Zarda $\square$ daily. Each packet contains 10 gms of tobacco.

III ${ }^{\text {rd group }}$ contained 25 subjects having history of cigarette smoking more than 20 cigarettes day \& night since 9 to 10 years.

$\mathrm{IV}^{\text {th }}$ group contained 25 subjects having of history of drinking alcohol of any kind more than 10 years. They use to drink alcohol more than $180 \mathrm{ml}$ dally.

$\mathrm{V}^{\text {th }}$ group was also called functional Impotant's group contained subjects, having history of functional impotence.

The semen samples were analyzed for volume, motility \& sperm count. The ascorbic acid \& fructose levels were obtained calorimetrically.

Both these physical \& biochemical parameters were compared between control group \& tobacco, chewers, smokers, alcoholics, and functional impotant's group.

Table \& Fig shows ascorbic acid concentration in five groups. The ascorbic concentration goes on decreasing from group $1^{\text {Th to }} \mathrm{v}^{\text {th }}$ group. It is highest in control group, than other groups. It shows that as quality of semen goes on decreasing. It also indicates that as ascorbic acid goes on decreasing fertility also decreases.

It means that tobacco, alcohol \& functional impotence affect ascorbic levels in semen.

Ascorbic acid concentration in the body depends upon dietary intake of fresh fruits. Which are rich sources of ascorbic acid (Dr. Shirole C. D. 1978) the subjects belonging to the addicts \& functional important group have less dietary intake of fresh fruits? This is also one of the reasons for lowering the ascorbic acid concentration.

In some studies done by others same observation is noted. Fertile group having higher concentrations of ascorbic acid than infertile group (Dr. Shirole C. D. 1978) Philips \& Co- workers also found that bulls of high fertility groups semen containing 3 to $8 \mathrm{mg} \%$ ascorbic acid where as low fertility bulls may have less than $2 \mathrm{mg}$ $\%$ In contrast to the above findings some workers observed that, fertile group shows lower ascorbic acid concentration than impaired semen (Vishwanar P.S. 1966)

The Significance of fructose in seminal plasma is a controversial subject. Some observed no statistical relationship between fructose level \& sperm concentration. But others demonstrated definite inverse relationship between fructose \& sperm count. (4) (48)

Our findings are not in conformity with those of Scheoenfeld et al, Moon \& Bing who have reported the absence of any difference in fructose levels between normospermic,oligospermic \& azoospermic.

In some studies smokers were found to have semen volumes significantly smaller than non smokers (Andrologia, March - April 1991)

In our study decrease in volume from $\mathrm{I}^{\text {st }}$ group to $\mathrm{V}^{\text {th group }}$ is very less in amount. It indicates that in addiction \& functional impotence cases, there are no much any changes in volume of semen.

Alcohol, Tobacco chewing \& Smoking also affects the motile count. In functional impotants group, there is slight reduction in motile count.

In functional impotant's group it is slightly reduction in motile count.

In control group the total sperm count is 180.46 / millions / ejaculate while it is decreased in remaining groups. It is lowest in alcoholics groups. Thus the sperm count is greatly affected by alcohol drinking \& smoking.

In functional impotants group it is slightly reduced. There is no any causative factor. It is decreased due to emotional disturbances, there is hormonal imbalance taking place \& affecting sperm production.

The studies of others show that reproduction is mainly based on hormonal balance but emotional upset can disturb the hormonal balance \& reproduction (Patrurkar, 1978)

The impact of tobacco on reproductive capacity is noted. Similar to our studies decrease in sperm density in male smokers was reported (Raboch journal 1975)

Similar results with the study of Richard D Amelar and in other studies (Dr. Martin F. Vine, 1979)

Stopping smoking increases sperm count. A study of three smokers who we followed for 5-15 months after stopping smoking reported that their sperm counts rose $50-80 \%$ suggesting that toxic chemicals in smoker are responsible \& any reduction in the sperm count is reversible. (Fertility sterility Journal, 1994)

Some studies show that testosterone level in sperm of smokers was fond to be significantly lower than that of non - smokers indicating its 
Decreased synthesis by the interstitial leyding cells. (Futility sterility Journal, Aug .1982) Reduction of the testosterone level in serum of smokers below that of non smokers was also reported by Briggs, in six healthy smokers who were smoking more than 30 cigarettes a day.

Dr. Vine also reported that smokers have lower sperm count. $13 \% 17 \%$ lower than non - smoker.

But in the journal of Androdlogia, it is found that cigarette smoking revealed no detrimental effect on spermatogenesis.

Baul Kotwani \& Malik reported that chronic investigation of alcohol results in diminished spermatogenesis due to liver damage. They also reported that of total sterility cases, excessive alcohol taking are $10 \%$ cases, while moderate alcohol taking are $5 \%$ cases.

In Lancet 1953 same findings are obtained.

Excesses alcohol causes damage to the liver cells, thus hamper the metabolism of alcohol causes damage to the liver cells, and thus hamper the metabolism of alcohol. There is accumulation of toxic products with further cause's damage to liver cells. All these processes prevent metabolism of testosterone. (Davidson's principles \& practice of Medicine)

\section{Summary And Conclusions}

Tobacco chewing, smoking, alcoholic drinking \& functional impotence does not affect the volume, motility of semen.

The total count \& total motile count is significantly decreased in tobacco chewers, smokers \& alcoholics. The total count is decreased in functional impotant's group but this is not significant but decrease in total motile sperm count is significant.

The ascorbic acid concentration in semen of these studied four groups is lowered as compared to control group. But this decreased concentration is significant. These findings indicate that lowered concentration of ascorbic acid.

While another biochemical parameter fructose, it's concentration is significantly increased in studied four groups as compared to control group. It shows that percentage of fructose in the semen depends on sperm concentration $\&$ it is inversely proportional to the sperm concentration.

Infertility is very tragic \& major problem today. In ill-literate people infertility is considered a social stigma. Factors affecting the infertility are coming from both male \& female equally. So an investigation of both male $\&$ female is very essential. Some couples are infertile due to their ignorance \& inadequate information. They must be motivated about such bad habits like smoking, alcohol drinking \& tobacco chewing.

The shyness, ignorance \& fear about functional impotence also must be removed.

The present study indicates that addiction \& functional impotence causes decrease in male fertility potential. However, Further studies are required in this filed.

Bilovgaphy

[1] All India Institute of Medical Sciences, New Delhi publication on December 12,1988

[2] Andrologia: 23(2); 141-4, March - April 1991.

[3] Briggs MH: Cigarette smoking and infertility in man. Med J. Aust. 1: 616, 1973.

[4] Devidson's Principles and practice of Medicine.

[5] Fertility Sterility Journal, Vol. 38, No. 2 Aug .1982.

[6] Fertility sterility Journal 6 (1); 35-43, 1994

[7] Dr. Maarityn F Vine: University of North Carolina, Jan 7, 1979.

[8] Moon KH, Binge RG.: Observations on the biochemistry of human semen. Fertility sterility 19: 186,1968

[9] Paturkar : Semen analysis in infertile couples, 1978

[10] Raboch Journal, Mella J: Smoking and fertility, BR. J. sexual med: 35, 1975.

[11] Schoenfeld CY, Amelan RD, Dubin L, Numeroff M: Prolactin , Fructose Zinc levels in human seminal plasma. Fertility sterility J.32: 206, 1979.

[12] Shirole CD: Some of the biochemical constituents in human semen in health and disease, 1978

[13] Vaishwanar PS, Deshkar B.V.: Am. J. Obst . Gynecol, Aug .15, 1966. 